\title{
Could Carbon Breath Test Measurement Accurately Reflect Gastric Emptying of Liquid Nutrient Meal in the Critically III Patients?
}

(Gut 2011;60:1336-1343)

Ji Won Kim

Department of Internal Medicine, SMG-SNU Boramae Medical Center; and Department of Internal Medicine and Liver Research Institute, Seoul National University College of Medicine, Seoul, Korea

\section{Summary}

It is assumed that delayed gastric emptying (GE) occurs frequently in critically ill patents, but the overall prevalence of delayed GE in these patients using scintigraphy remains uncertain. Recently Chapman et $\mathrm{al}^{1}$ reported that GE was demonstrated to be slow in about $50 \%$ of intensive care unit patient using scintigraphy and the breath test appears to be an accurate alternative to scintigraphy for the measurement of GE in critically ill patients. Studies were performed in the 25 unselected, mechanically ventilated patients and 14 healthy controls. A nasogastric (NG) tube was inserted to all of healthy controls for the purpose of the study and its position was verified by $\mathrm{pH}$ measurement of $\mathrm{NG}$ tube aspirates. Prior to the study, the gastric contents were aspirated and a test meal which consisted of $100 \mathrm{~mL}$ Ensure $(1 \mathrm{kcal} / \mathrm{mL})$ doped with $20 \mathrm{MBq}^{99 \mathrm{~m}}$ Technetium sulphur colloid and $75 \mathrm{KBq}$ octanoic acid, $\left[{ }^{1-14} \mathrm{C}\right]$ sodium salt was infused into the stomach via the NG tube over 5 minutes. The scintigraphic measurement of GE was performed in patients and healthy controls using a mobile $\gamma$ camera with 3 minute dynamic frame acquisition.
Gastric meal retention (scintigraphy) at 60, 120, 180 and 240 minutes, breath test $\mathrm{t}_{50}\left(\mathrm{BT}_{50}\right)$ and $\mathrm{GE}$ coefficient were determined. Before and after the study, the gastric residual volume (GRV) was determined every 6 hour and the total volumes were documented for 24 hour preceding the study.

The authors demonstrated that, of the 24 patients with scintigraphy data, GE was delayed at 120 minutes in about $50 \%$ of intensive care unit patients. Patients with delayed GE had greater severity of illness on admission to the intensive care unit, and were more likely to have been admitted with trauma, sepsis and respiratory failure. Breath tests correlated well with scintigraphy in both patients and healthy controls (\% retention at 120 minutes vs $\mathrm{BTt}_{50} ; \mathrm{r}^{2}=0.57$ healthy; $\mathrm{r}^{2}=0.56$ patients; $P \leq 0.002$ for both). There was also a strong correlation between breath measurements and intragastric retention in both patients and healthy controls. In patients with slow GE there was a trend for a reduced volume nutrient delivery, and energy delivery was reduced in the patients with slow GE (normal GE 1,920 vs slow GE 510 kcal; $P$ $=0.047$ ). Therefore, they concluded that GE was delayed in about half of critically ill patients and markedly delayed in about $20 \%$, and breath tests correlated well with scintigraphy and could

Received: March 4, 2012 Revised: March 16, 2012 Accepted: March 20, 2012

(c) This is an Open Access article distributed under the terms of the Creative Commons Attribution Non-Commercial License (http://creativecommons. org/licenses/by-nc/3.0) which permits unrestricted non-commercial use, distribution, and reproduction in any medium, provided the original work is properly cited.

*Correspondence: Ji Won Kim, MD

Department of Internal Medicine, SMG-SNU Boramae Medical Center, Seoul National University College of Medicine, 20 Boramae-ro 5-gil, Dongjak-gu, Seoul 156-707, Korea

Financial support: None.

Tel: +82-2-870-2221, Fax: +82-2-870-3863, E-mail: kjwjor@snu.ac.kr

Conflicts of interest: None. 
be used as a valid method for the measurement of GE in these patients for research purposes to quantify the effects of promotility agents.

\section{Comment}

Delay in GE is a common problem in critically ill patients. Patients receiving enteral feeding are closely monitored to detect a delay of GE, assess feeding tolerance, and prevent aspiration pneumonia. Although the most common practice for assessing GE is to measure the aspirated GRV, this is an unreliable method that fails to differentiate enteral fomula from normal gastric secretions. Therefore, it is important to establish an appropriate method for the evaluation of GE to avoid unnecessary interruptions of enteral feeding. ${ }^{2}$

Scintigraphy is considered as the gold standard for evaluating GE, because it provides information on the anatomical and physiologic aspect of $\mathrm{GE}$ and provides quantitative results. ${ }^{3}$ Although scintigraphy is considered the ideal method for assessing GE, this method shows a great inter- and intrasubjective variation and intersubject variation and standardization of the technique is lacking. ${ }^{4}$ The limitation of scintigraphy is that it does not measure gastric and salivary secretions that are part of the GRV. ${ }^{5}$ In addition, scintigraphy is an impractical method for the assessment of critically ill patients because it requires frequent imaging during 2-4 hours and exclusive use of $\gamma$-scintillation camera for this period.

In the breath test, a stable nonradioactive isotope, carbon-13 $\left({ }^{13} \mathrm{C}\right)$, is used to label a test meal containing a small amount of octanoic acid or sodium acetate, neither of which is absorbed in the stomach. ${ }^{6}$ Although breath test is a feasible method to evaluate $\mathrm{GE}$ at the bedside with advantage of avoiding radiation exposure, this is indirect methods for measuring GE. The time for the distribution an elimination of ${ }^{13} \mathrm{CO}_{2}$ and its passage through the blood bicarbonate system may affect the excretion of ${ }^{13} \mathrm{CO}_{2}$ in the exhaled air. Chew et $\mathrm{al}^{7}$ conducted a study comparing breath test and scintigraphy in patients and normal volunteers. They found a significant correlation between scintigraphy and breath test, with most significant correlation between times to maximum ${ }^{13} \mathrm{CO}_{2}$ and gastric half-clearing time of gallium- $67\left({ }^{67} \mathrm{Ga}\right)$, as measured by scnitigraphy, and gastric $\mathrm{T}_{1 / 2}$, as determined by the breath test $(\mathrm{r}=0.88 ; P<0.005)$.
In this study, the authors determined the prevalence of slow GE, which is likely to affect the success of nutrient delivery, and the accurate measurement of GE in critically ill patients. They also demonstrated that the magnitude of delay in GE is frequently substantial in critically ill patients, and GRV measurement correlated well with GE. There are several limitations that should be considered in this study. When scintigraphy was performed, 3-dimensional pictures was not generated due to the necessity for the patients to remain supine. In addition, the breath test technique requires $\mathrm{GE}$, duodenal absorption, liver metabolism and respiratory excretion to occur. GE is thought to be the rate-limiting step in this process, but it is possible that in critically ill patients marked derangements in the other step may occur.

In conclusion, this report is the first study to examine the prevalence of delayed GE in a heterogeneous critically ill populations using scintigraphy. These data suggests that breath test can be used as a convenient method for the measurement of GE in critically ill patients with cumulative GRV as low as $150 \mathrm{~mL}$ measured over 24 hour.

\section{References}

1. Chapman MJ, Besanko LK, Burgstad CM, et al. Gastric emptying of a liquid nutrient meal in the critically ill: relationship between scintigraphic and carbon breath test measurement. Gut 2011;60:13361343.

2. McClave SA, Lukan JK, Stefater JA, et al. Poor validity of residual volumes as a marker for risk of aspiration in critically ill patients. Crit Care Med 2005;33:324-330.

3. Akkermans LM, Van Isselt JW. Gastric motility and emptying studies with radionuclides in research and clinical settings. Dig Dis Sci 1994;39(12 suppl):95S-96S.

4. House A, Champion MC, Chamberlain M. National survey of radionuclide gastric emptying studies. Can J Gastroenterol 1997;11:317321.

5. Soulsby CT, Khela M, Yazaki E, Evans DF, Hennessy E, PowellTuck J. Measurements of gastric emptying during continuous nasogastric infusion of liquid feed: electric impedence tomography versus gamma scintigraphy. Clin Nutr 2006;25:671-680.

6. Ritz MA, Fraser R, Edwards N, et al. Delayed gastric emptying in ventilated critically ill patients: measurement by ${ }^{13} \mathrm{C}$-octanoic acid breath test. Crit Care Med 2001;29:1744-1749.

7. Chew CG, Bartholomeusz FD, Bellon M, Chatterton BE. Simultaneous ${ }^{13} \mathrm{C} /{ }^{14} \mathrm{C}$ dual isotope breath test measurement of gastric emptying of solid and liquid in normal subjects and patients: comparison with scintigraphy. Nucl Med Rev Cent East Eur 2003;6:29-33. 